\title{
Lactate Dehydrogenase Isoenzyme Patterns in Bird, Carp and Mammalian Sera
}

\author{
Dagmar Heinová, Ján Blahovec and Ivan Rosival
}

Department of Chemistry, Biochemistry and Biophysics, University of Veterinary Medicine, Košice, Slovakia

Summary: Isoenzyme patterns of lactate dehydrogenase (EC 1.1.1.27) in avian sera are described and compared with those of carp and some mammals. The predominant portion of lactate dehydrogenase in avian sera was concentrated in the muscular form of the enzyme (lactate dehydrogenase 5). Most mammalian sera (with the exception of rat serum) showed a different pattern, in which the main portion of lactate dehydrogenase activity migrated in the first three anodic fractions. Fish serum lactate dehydrogenase isoenzymes were distributed similarily to those of mammals.

The electrophoretic mobility of bird lactate dehydrogenase isoenzymes in a $\mathrm{pH}$ gradient of 3 to 9 was different from that of carp, cattle and rabbit. Bird lactate dehydrogenase isoenzymes were localized in the $\mathrm{pH}$ region of 5.8 to 8.1. In contrast, the mammalian isoenzymes were more acidic, with $\mathrm{pI}$ values in the range of 4.5 to 7.3 . Lactate dehydrogenase isoenzymes of carp migrated in a narrow $\mathrm{pH}$ range of 5.2 to 6.5 .

\section{Introduction}

Five isoenzymes of lactate dehydrogenase ${ }^{1}$ ) exist in tissues of most vertebrates. Their molecular properties and catalytic characteristics have been studied in detail (1-5), permitting an explanation of their physiological functions and relative distribution, especially in heart and skeletal muscle cells. There are also many reports concerning lactate dehydrogenase isoenzymes in sera of healthy animals and humans, as well as in the sera of individuals with different organ disorders $(6-12)$. The detailed knowledge of these enzymes is important for clinical diagnosis both in human and veterinary medicine.

Despite a profound understanding of lactate dehydrogenases, there is a lack of data concerning their relative distribution in avian sera. This gap in our knowledge of these enzymes is probably due to the fact that electrophoretic techniques routinely used in separating mammalian lactate dehydrogenase isoenzymes do not produce a satisfactory separation of bird enzymes (3).

It is known that the charge of a protein and, therefore, its mobility in an electric field, varies with the $\mathrm{pH}$ of its environment. Maximum resolution is achieved when the proteins of interest have widely varying electrical charges. Conversely, no or poor separation of the proteins is achieved when there are only small differences in the electrical charges of molecules at a given $\mathrm{pH}$

\footnotetext{
1) Enzyme:

Lactate dehydrogenase (EC 1.1.1.27)
}

value. Changing the $\mathrm{pH}$ of the electrophoresis media may alter the charges on respective proteins, thus producing a better separation. Generally, an anodic buffer system of $\mathrm{pH} 8.6$ is chosen for separation of the five lactate dehydrogenase isoenzymes. At $\mathrm{pH} 8.6$ their electrophoretic migration depends on the migration of the two pure types, i.e. the $\mathrm{H}_{4}$ and $\mathrm{M}_{4}$ forms (3). The more widely the two homotetramers differ in charge (the case of mammalian lactate dehydrogenases), the more separable are the hybrids by electrophoresis. In the case of bird lactate dehydrogenases, the two pure types migrate relatively close together toward the negative pole at $\mathrm{pH} 8.6$, and observation of the hybrid forms under these conditions is very difficult (3). To avoid this difficulty we chose a gradient of $\mathrm{pH} 3$ to 9 for the electrophoretic separation of bird lactate dehydrogenase isoenzymes. By this technique we achieved a good resolution of all the five forms of the enzyme in both chicken and pheasant serum.

The aim of our work was to separate and characterize the relative distribution of lactate dehydrogenase isoenzymes in sera of avian origin. We compared the separation patterns with those of lactate dehydrogenase isoenzymes in the sera of some mammals and fish. Preliminary results of our work have been published previously (in Slovak) (13).

\section{Materials and Methods}

Animals and serum samples

Sera from the following animal species were investigated: fowl, pheasant, fish, horse, cattle, sheep, rabbit, dog and rat. They were 
obtained from adult, male and female, clinically healthy animals. The blood collection for the serum samples was performed by standard procedures. No haemolysed sera were used for the examinations.

Determination of total lactate dehydrogenase activity as well as separation of the isoenzymes were performed on the same day as the blood collection.

Catalytic activity of lactate dehydrogenase was determined using a colorimetric method according to Sevela \& Továrek (14) at $37^{\circ} \mathrm{C}$.

\section{Electrophoretic separations}

Lactate dehydrogenase isoenzymes were separated using the electrophoretic system PhastSystem (Pharmacia LKB, Sweden). Separation techniques were used as follows:

1. Gradient polyacrylamide gel electrophoresis with continuous 10 to $15 \%$ gradient gel zone and $2 \%$ cross-linking (PAGE $10-15$ ). Separation conditions: $400 \mathrm{~V}, 10.0 \mathrm{~mA}, 45 \mathrm{~min}$ separation time. Separations of lactate dehydrogenase isoenzymes were carried out with cooling at $4{ }^{\circ} \mathrm{C}$ and with a buffer system of $0.88 \mathrm{~mol} / 1 \mathrm{~L}$ alanine $/ 0.25 \mathrm{~mol} / / \mathrm{Tris} \mathrm{pH} 8.8$.

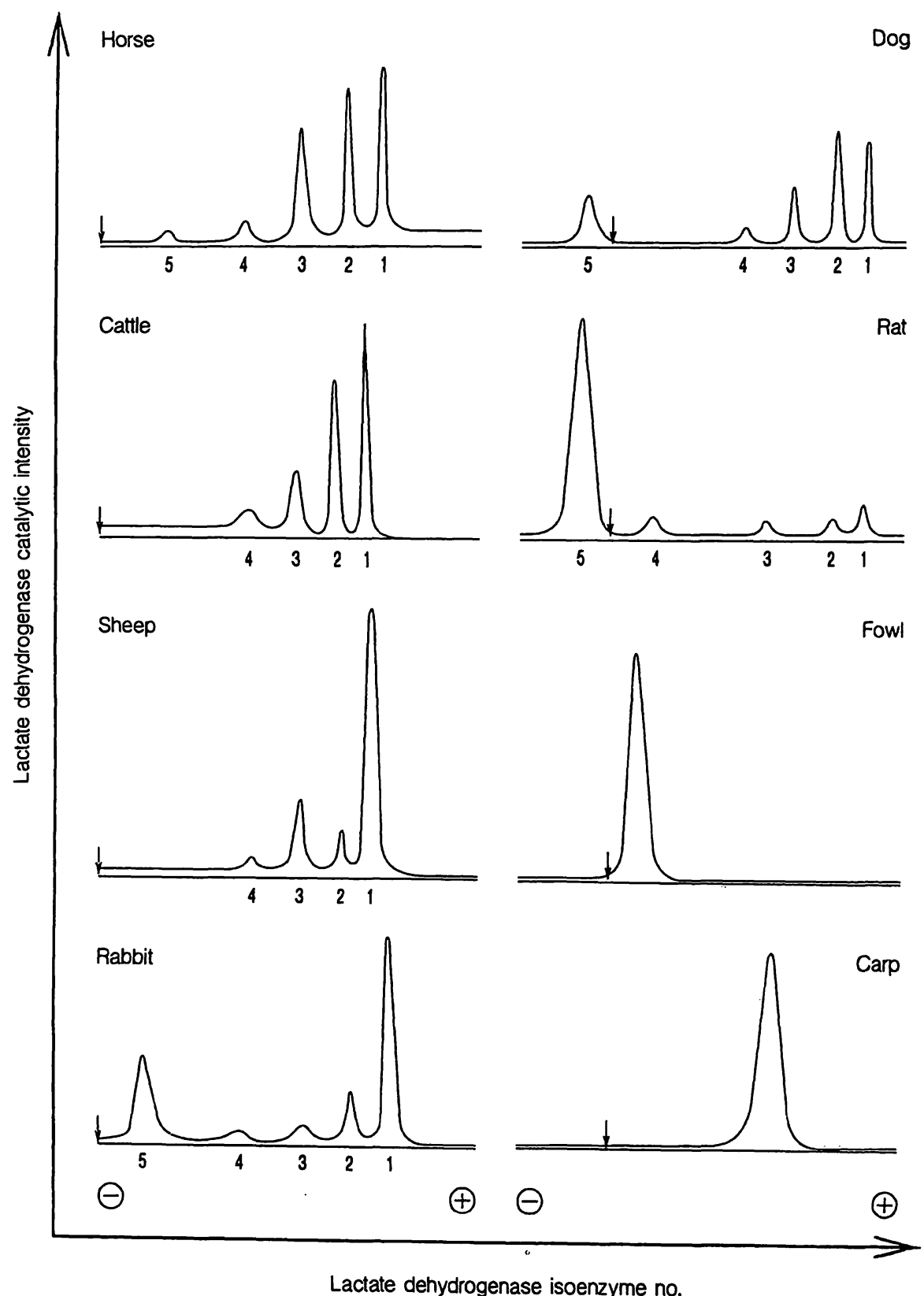

Fig. 1 Separations of serum lactate dehydrogenase isoenzymes of various animal species in a concentration gradient of polyacryl- at

Fowl

arp application.
2. Isoelectric focusing (IEF) with pH range 3 to 9 in homogeneous $5 \%$ polyacrylamide gel containing Pharmalyte ${ }^{\circledR}$ carrier ampholytes. Separation conditions: $2000 \mathrm{~V}, 2.5 \mathrm{~mA}, 15^{\circ} \mathrm{C}, 20$ min separation time.

Before their application to the gel, sera were diluted in $50 \mathrm{mmol} / \mathrm{l}$ Tris/ $\mathrm{HCl} \mathrm{pH} 7.5(1: 3)$.

\section{Detection and quantification of patterns}

Lactate dehydrogenase isoenzymes were detected with nitroblue tetrazolium according to Michálek \& Marcanik (6). pI calibration kit proteins were stained with Coommassie Blue R. PhastImage system (Pharmacia LKB, Sweden) was used for densitometric scanning $(613 \mathrm{~nm})$ of the pattern and for determination of the relative distribution of the isoenzyme fractions.

To identify individual lactate dehydrogenase fractions on the isoelectrophoretogram, the fraction nearest to the anode was designated lactate dehydrogenase 1 , and that nearest to the cathode lactate dehydrogenase 5 .

The relative distribution of the isoenzymes in sera was expressed as a percentage of total lactate dehydrogenase activity.

amide $(10-15 \%)$ at $\mathrm{pH} 8.8$; an arrow indicates the site of sample 
The precision of the isoelectric focusing method for separation of the fowl lactate dehydrogenase (LD) isoenzymes was investigated using eight series of the same serum with eight samples in each of the series. The values of the coefficient of variance (CV) within series were as follows: $13 \%$ for $\mathrm{LD}_{1}, 12 \%\left(\mathrm{LD}_{2}\right), 6 \%\left(\mathrm{LD}_{3}\right), 4 \%$ $\left(L D_{4}\right)$ and $2 \%\left(L D_{5}\right)$. The values of the coefficient of variance between series ( $n=8 ; 8$ series) were $17 \%\left(L_{1}\right), 14 \%\left(L D_{2}\right), 8 \%$ $\left(\mathrm{LD}_{3}\right), 3 \%\left(\mathrm{LD}_{4}\right)$ and $3 \%\left(\mathrm{LD}_{5}\right)$.

\section{Results}

Figure 1 illustrates a typical densitometric pattern of serum lactate dehydrogenase isoenzymes of various animal species after their separation in a concentration gradient of polyacrylamide (10-15\%). At $\mathrm{pH} 8.8$ mammalian serum lactate dehydrogenase isoenzymes were separated with a good resolution, whereas bird and carp sera produced only one, somewhat diffuse lactate dehydrogenase zone under these conditions.
A better separation of lactate dehydrogenase isoenzymes of bird and carp sera was achieved using gel isoelectric focusing with a pH range of 3 to 9 (IEF 3-9). Using the isoelectric focusing technique it was possible to identify five well resolved fractions, especially on the avian enzymogram. A typical densitometric pattern of the serum isoenzymes of fowl, pheasant, carp and some mammals after their separation in a pH gradient is illustrated in figure 2.

Lactate dehydrogenase catalytic activity and relative distribution (\%) of its isoenzymes in sera of the investigated animals are given in table 1. A comparison of these values showed that the relative distributions of lactate dehydrogenase isoenzymes in bird, carp and mammalian sera are different. The predominant portion of fowl serum lactate dehydrogenase activity was concentrated in the muscle form of the enzyme (lactate dehy-

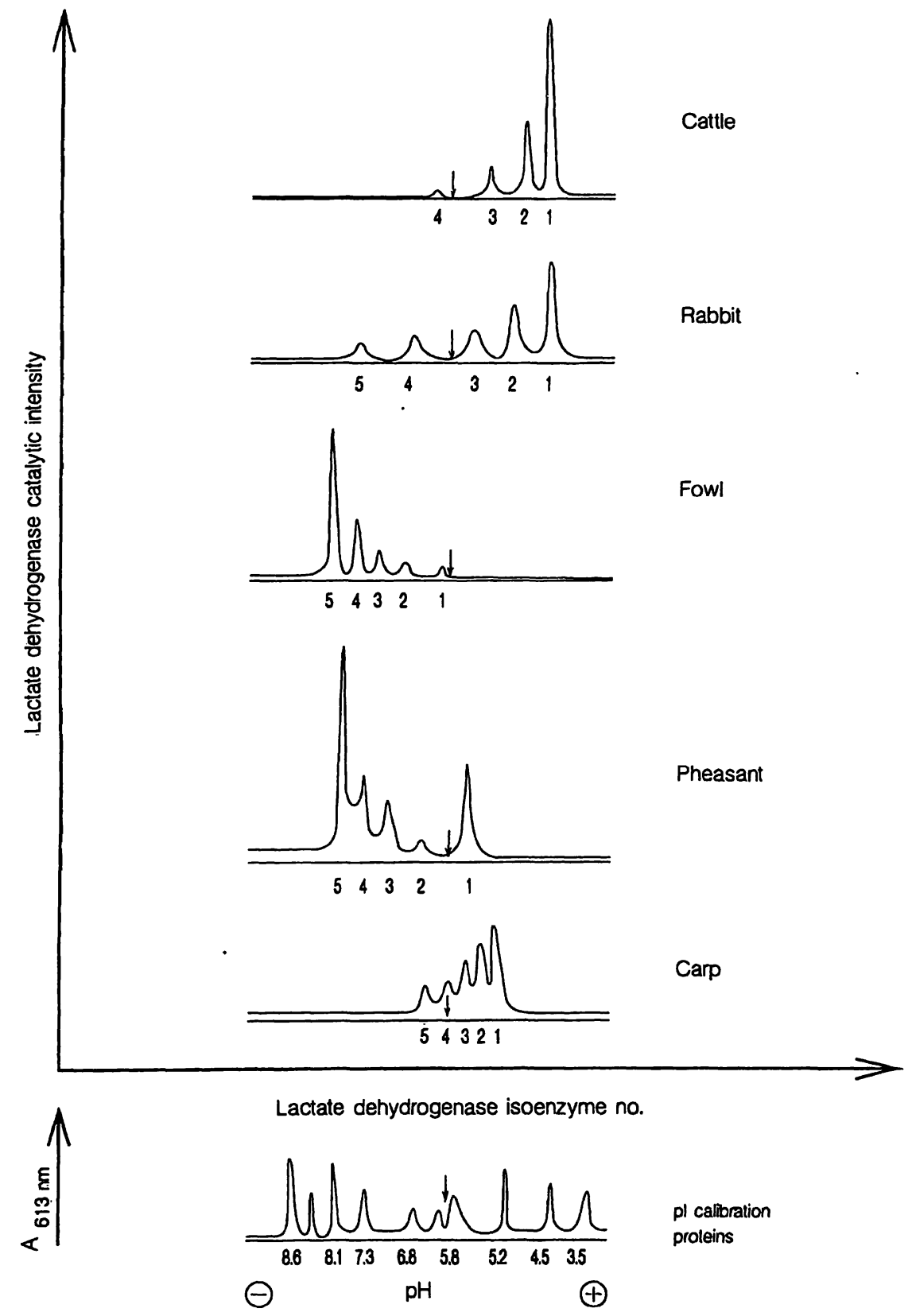

Fig. 2 Separations of serum lactate dehydrogenase isoenzymes of various animal species in a $\mathrm{pH}$ gradient of 3 to 9; an arrow indicates the site of sample application. 
Tab. 1 Lactate dehydrogenase catalytic activity (U/I) and relative distribution of its isoenzymes in sera of various animal species $(\hat{x} \pm S D, n=6)$

\begin{tabular}{|c|c|c|c|c|c|c|}
\hline \multirow[t]{2}{*}{ Species } & \multirow{2}{*}{$\begin{array}{l}\text { Catalytic } \\
\text { activity } \\
\text { (U/I) }\end{array}$} & \multicolumn{5}{|c|}{ Lactate dehydrogenase isoenzyme (\%) } \\
\hline & & 1 & 2 & 3 & 4 & 5 \\
\hline Fowl & $470 \pm 18$ & $3 \pm 1$ & $5 \pm 2$ & $6 \pm 1$ & $23 \pm 3^{\prime}$ & $66 \pm 4$ \\
\hline Pheasant & $163 \pm 6$ & $23 \pm 2$ & $4 \pm 1$ & $12 \pm 2$ & $16 \pm 2$ & $44 \pm 3$ \\
\hline Carp & $80 \pm 12$ & $46 \pm 6$ & $26 \pm 3$ & $15 \pm 2$ & $10 \pm 2$ & $3 \pm 1$ \\
\hline Horse & $111 \pm 5$ & $35 \pm 1$ & $29 \pm 2$ & $28 \pm 2$ & $7 \pm 2$ & $1 \pm 0.4$ \\
\hline Cattle & $403 \pm 15$ & $53 \pm 2$ & $35 \pm 1$ & $11 \pm 1$ & $1 \pm 0.2$ & \\
\hline Sheep & $286 \pm 7$ & $69 \pm 2$ & $8 \pm 1$ & $17 \pm 2$ & $2 \pm 0.5$ & \\
\hline Rabbit & $104 \pm 8$ & $68 \pm 3$ & $13 \pm 3$ & $3 \pm 1$ & $3 \pm 1$ & $14 \pm 4$ \\
\hline Dog & $49 \pm 4$ & $23 \pm 4$ & $34 \pm 2$ & $17 \pm 2$ & $6 \pm 2$ & $17 \pm 5$ \\
\hline Rat & $163 \pm 6$ & $9 \pm 3$ & $5 \pm 2$ & $1 \pm 0.5$ & $5 \pm 2$ & $78 \pm 9$ \\
\hline
\end{tabular}

drogenase 5) (66\%), followed by lactate dehydrogenase $4(23 \%)$. Lactate dehydrogenase 1 to 3 occurred in low amounts with fairly similar proportions (3-6\%) (tab. 1). The muscle isoenzyme was also the main fraction in pheasant serum (44\%) followed by heart homotetramer (23\%). Hybrid forms of the pheasant enzyme, i. e. lactate dehydrogenase 4, 3 and 2 were present in smaller amounts $(16,12$ and $4 \%$, respectively). Most mammalian sera (with the exception of rat serum) showed a reverse pattern: the main portion of serum lactate dehydrogenase activity migrated in the first three anodic fractions, while lactate dehydrogenases 4 and 5 made only minor contributions (Tab. 1). The relative distributions of lactate dehydrogenase isoenzymes in mammalian sera listed in table 1 largely correspond to those published in the literature $(6,8,9,11)$.

The distribution of carp serum lactate dehydrogenase isoenzymes was similar to those of mammals, i.e. lactate dehydrogenases 1 to 3 were the major fractions (46, 26 and $15 \%$, respectively) (tab. 1).

\section{Discussion}

It has previously been observed that at $\mathrm{pH} 8.6$ it is very difficult to separate bird lactate dehydrogenase isoenzymes (3). Our results showed that an effective method for their separation is gel isoelectric focusing with a $\mathrm{pH}$ range of 3 to 9 . With this technique it was possible to separate bird lactate dehydrogenase isoenzymes with good resolution of all the five forms of the enzyme and to characterize their relative distribution in sera of healthy individuals (tab. 1). Moreover, the technique of isoelectric focusing revealed differences in electrophoretic properties of bird, fish, and mammalian lactate dehydrogenase isoenzymes (fig. 2). Bird lactate dehydrogenase 1 to lactate dehydrogenase 5 were localized in the cathodic part of isoelectrophoretogram in the region spanning $\mathrm{pH} 5.8$ to 8.1 . The mammalian lactate dehydrogenase isoenzymes were found to be more acidic than their avian counterparts, with $\mathrm{pI}$ values in the range of 4.5 to 7.3. From the literature it is known that bird and mam- malian lactate dehydrogenases differ in the amino acid composition of their $\mathrm{H}$ and $\mathrm{M}$ subunits (15). Comparing avian and mammalian enzymes, the avian $\mathrm{H}$ and especially $\mathrm{M}$ molecule contain more basic amino acid residues, in particular histidine (15). This explains the different electrophoretic mobilities of avian and mammalian lactate dehydrogenase isoenzymes in a $\mathrm{pH}$ gradient. An apparent shift of the isoelectric points of bird lactate dehydrogenase isoenzymes towards basic values also explains the unwillingness of bird lactate dehydrogenases to separate at $\mathrm{pH} 8.6$,i.e. at a $\mathrm{pH}$ value routinely used for the separation of mammalian lactate dehydrogenase isoenzymes.

Differences were also observed between the electrophoretic properties of bird and carp lactate dehydrogenases 1 to 5 . Fish lactate dehydrogenases $\mathrm{H}_{4}$ to $\mathrm{M}_{4}$ migrated relatively close together in quite a narrow region of $\mathrm{pH}$ 6.5 to 5.2 (fig. 2). Their localization in the $\mathrm{pH}$ gradient was also different from that of mammalian lactate dehydrogenases.

From studies on the evolution and phylogenetic relationships of species (2), it is known that heart and skeletal muscle lactate dehydrogenases of mammals and birds have similar catalytic properties. Presumably, the different electrophoretic properties of lactate dehydrogenase isoezymes described in this work reflect the different phylogenesis of bird, carp and mammalian lactate dehydrogenase molecules.

The efficient resolution of all five forms of bird lactate dehydrogenase isoenzymes by exploiting their different pI values represents a major contribution to the detailed understanding of these enzymes. We believe that the results described in this paper will find their application in animal clinical biochemistry as well as in toxicological studies.

\section{Acknowledgements}

The authors thank Professor Eitan Bogin;(Tel Aviv University) for reading the manuscript, and for valuable discussion and advice. Mrs. Tatiana Hudáková provided valuable technical assistance. 


\section{References}

1. Plagemann PGW, Gregory KF, Wróblewski F. The electrophoretically distinct forms of mammalian lactic dehydrogenase. I. Distribution of lactic dehydrogenase in rabbit and human tissues. J Biol Chem 1960; 235:2282-7.

2. Kaplan NO, Ciotti MM, Hamolsky M, Bieber RE. Molecular heterogeneity and evolution of enzymes. Coenzyme analogs are useful for studying the evolution, classification, and differentiation of enzymes. Science 1960; 131:392-7.

3. Cahn RD, Kaplan NO, Levine L, Zwilling E. Nature and development of lactic dehydrogenases. The two major types of this enzyme form molecular hybrids which change in makeup during development. Science 1962; 136:962-9.

4. Wilson AC, Cahn RD, Kaplan NO. Functions of the two forms of lactic dehydrogenase in the breast muscle of birds. Nature $1963 ; 197: 19-24$.

5. Fondy TP, Pesce A, Freedberg I, Stolzenbach F, Kaplan NO. The comparative enzymology of lactic dehydrogenases. II. Properties of the crystalline $\mathrm{HM}_{3}$ hybrid from chicken muscle and of $\mathrm{H}_{2} \mathrm{M}_{2}$ hybrid and $\mathrm{H}_{4}$ enzyme from chicken liver. Biochemistry $1964 ; 3: 522-30$.

6. Michálek A, Marcanik J. The activity values of the isoenzymes of lactic acid dehydrogenases in the serum of farm animals (in Slovak). Vet Med (Praha) 1975; 20:199-205.

7. Thornton JR, Lohni D. Tissue and plasma activity of lactic dehydrogenase and creatine kinase in the horse. Equine Vet $J$ $1979 ; 11: 235-8$.

8. Beatty EM, Doxey DL. Lactate dehydrogenase and creatine kinase isoenzyme levels in the tissues and serum of normal lambs. Res Vet Sci 1983; 35:325-30.
9. Milne EM, Doxey DL. Lactate dehydrogenase and its isoenzymes in the tissues and sera of clinically normal dogs. Res Vet Sci 1987; 43:222-4.

10. Mackawa Masato. Lactate dehydrogenase isoenzymes. A review. J Chromatography 1988; 429:373-98.

11. Preus M, Karsten B, Bhargava AS. Serum isoenzyme pattern of creatine kinase and lactate dehydrogenase in various animal species. J Clin Chem Clin Biochem 1989; 27:787-90.

12. Aguilera-Tejero E, Mayer-Valor R, Gómes-Cárdenas G. Spectrophotometric method for differentiation of cardiac and hepatic lactate dehydrogenase activities in dogs. Am J Vet Res $1989 ; 50: 1128-30$.

13. Heinová D, Blahovec J. Lactate dehydrogenase isoenzymes in mammalian and fowl sera (in Slovak). Vet Med - Czech 1994; $39: 75-84$

14. Ševela $M$, Továrek J. A method for estimation of lactic dehydrogenase in body liquids (in Czech). J Czech Physiol 1959; 98:844-8.

15. Fondy TP, Kaplan NO. Structural and functional properties of the $\mathrm{H}$ and $\mathrm{M}$ subunits of lactic dehydrogenase. Ann NY Acad Sci $1965 ; 119: 888-903$.

Received June 16/November 6, 1995

Corresponding author: Dagmar Heinová, Katedra chémie, biochémie a biofyziky, Univerzita veterinárskeho lekárstva, Komenského 73, SK-041 81 Košice, Slovakia 
